\title{
New Phenomenon for Natural Control of Varroa Destructor in Honey Bee Colonies $A$. Mellifera L. in Libya
}

\author{
Alfallah, H.M. \\ University of Tripoli, Faculty of Agriculture, Plant Protection Department, Honey Bee Lab. Libya
}

\section{INTRODUCTION}

The ectoparasite varroa mite, Varroa destructor (Anderson and Trueman), is considered to be the most serious honey bee pest and the beekeeper cannot recognize it till the injuries appear, it feeds on the hemolymph (blood) of larvae, pupae, and adult bees. These external parasites also spread viruses during feeding, causes further injuries to the bee colony(Rosenkranz et al., 2010).

In Libya the varroa was first detected in the region of Al-Jabal Al-Akhader in 1976, where believed that it introduced by infected colonies that were imported from Bulgaria in 1974 to that region (Elshukri 2008).The mite then has spread covering almost the entire country in 1986 and has caused severe damage to the beekeeping industry, exceeded 50\% losses in honey bee colonies. The miticide used in the first time is Folbex VA (bromopropylate)as a fumigant strip, replaced with apistan (Fluvalinate)in 1990 where used for long time till the mite has ultimately develop resistance (Alfallah 2000). Bayvaroll have been registered in 1994,Apilife Var where imported from Italy in 2002 which consist from natural material, Amitrazimported in formula of fumigant stripalthough is not registered by the government.In summer 1995 I lost $75 \%$ from my apiary because of delaying treatment only one month, emerge wingless and shortened abdomen young bee, in the end the colonies collapsed,colonies would collapse within 2 years without periodic treatment,by removing sealed drone brood for four to fiveconsecutive times in the beginning of season without using other method for controlling varroa is sufficient for several years in my apiary.in the last 10 years most of beekeepers reduce their uses of chemicals and miticide importing has been reduced.Many diseases such as American, and European foul brood and some other diseases has been disappeared in the last eight year's because of honey bee organization stop their activity for importing bees from other countries. Many researchers try to spare the hive from residues of chemicals and found safe methods may introduced in program for alternative varroa control (AVC). Powdered sugar is most efficacious when it can be applied early in the season and exploit a winter brood-free period (Berry et al. 2012). Clove oil and tobacco extract both proved to be equally effective where gave the highest number of fallen Varroa mites (Rashid et al 2014). Good results achieved when lemon juice used with different concentrations with sugar syrup for controlling varroa on adult workers in honeybee colonies with little brood. (Abdel-Rahman and Rateb, 2008). In the United States they stop Amitraz from the marketing because of an issue of toxicity to bees through the strip plasticizer. (Jeff Pettis 2013). Researchers suggest that the drone-brood trapping method can be used as an element of an integrated control strategy to control varroa mites (Wantuch and Tarpy, 2009). By breeding mite-biting bees to control varroa, researcher found that it was possible to increase the proportion of chewed mites in the breeding population. Their results show that the trait is heritable. (Greg Hunt et al 2016)

\section{THE PHENOMENON}

As in every year in the end of first season of spring, we migrate our colonies to pasture of Ziziphus which leave the colonies during a blooming period one month, in the third or fourth visit on end of May season 2016 due to check for honey collection, I have started the work by opening the hive I surprised fromaccumulation of sand on the top of combs, when starting inspection and separate combs from each other to see inside the hive, I surprised again, there is big number of varroa mite fall on the sand on hive bottom board shown in fig.1,2.After completing the work, wandered in the region till meet shepherd of sheep in that area, asked him, he told me that a sandstorm occurs in the valley last 
week. This period characterized by increasing in air temperature $35 c^{\circ}$ to $38 c^{\circ}$, may this factor interfere for dropping varroa from bees, or the fine granules of sand encourage the workers to clean their bodies, also the layer of sand on thehive bottom board may prevent varroa mite from returning to bees, After 6 months despite, the continuous of brood rearing varroa level is very low

\section{CONCLUSION}

From my experience the heavy use of miticide resulting in residues and may be mite resistance without give chance to bees to develop self-defense, in the past if we don't treat the colonies the losses is high but it deference especially in five last years. Under conditions similar to Libya the environment may assist in this field, big number of varroa mite fallen is indicator to the host tolerate this infestation, it is important to analyze this phenomenon and benefit from factors interaction and decide which is the main reason is grooming, or sand, or temperature.

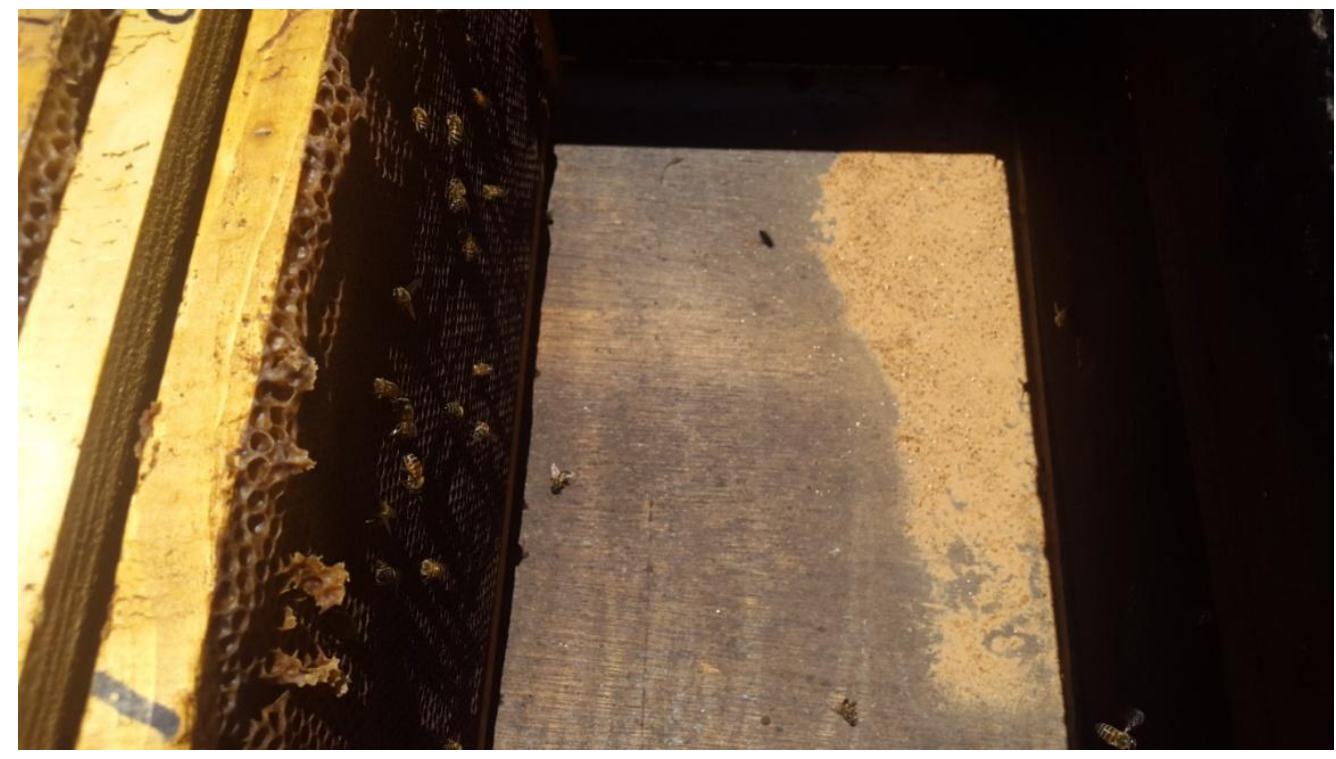

Fig1. Varroa on sand on bee hive bottom board.

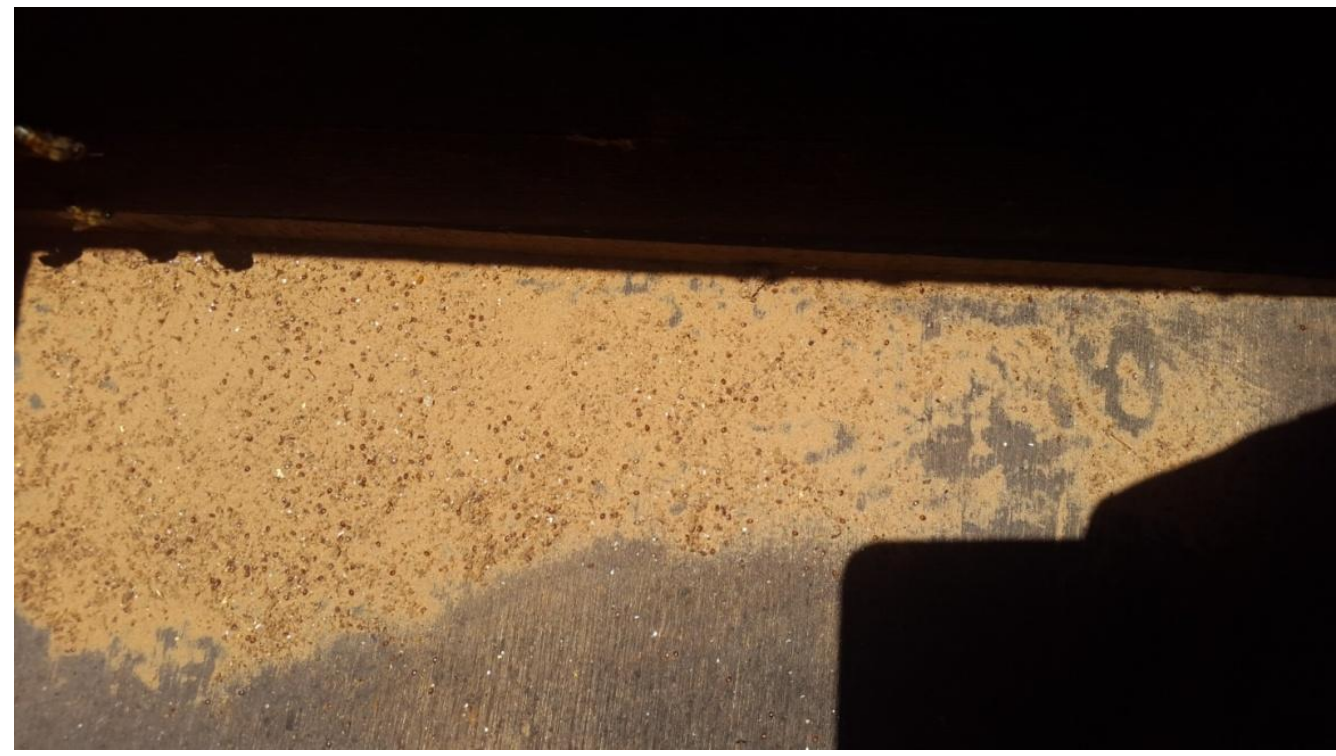

Fig2. Varroamite on sand on bee hive bottom board.

\section{REFERENCES}

[1] Alfallah H.M.2000.Efficacy comparison of some miticides for controlling Varroa destructor in honey bee colonies Apis mellifera L.Unpublished MS thesis, University of Tripoli, Libya.

[2] Berry, Jennifer A, OhadAfik, Maxcy P Nolan IV and Keith S Delaplane(2012)Revisiting powdered sugar for varroa control on honey bees (Apis mellifera L.)Journal of Apicultural Research 51(4): 367-368. 
[3] Elshukri F.G.2008.Survey study of ectoparasites on honey bee (Apis mellifera) in plain of Benghazi and Al-Jabal.Al-Akhadar region.Unpublished MS thesis, University of Garyounis.

[4] Rashid Mahmood, SaimaAsad, Shazia Raja, Atta ulMoshin, Elizabeth Stephen Wagchoure,GhulamSarwar, Noor Islam and Waqar Ahmad(2014) Control of Varroa destructor (Acari : Varroidae) in Apis mellifera (Hymenoptera : Apidae) by using Plant Oils and Extract. Pakistan J. Zool., vol. 46(3), pp. 609-615. http://dx.doi.org/10.1016/j.jip.2009.07.016

[5] Rosenkranz P, Aumeier P, Ziegelmann B, 2010. Biology and control of Varroa destructor. J InvertebrPathol 103: S96-S119.

[6] www.projectapism.org/wp-content/uploads/2013/06/Final-Rep...Amitraz residue transfer into honey from Apis mellifera hives ... Varroa destructor.... an acaricide to control Varroa destructor in honey bee hives but it...

[7] www.biobees.com/.../apis/LemonJuiceVarroaControl</...

Evaluation of lemon juice for controlling Varroa destructor in honeybee ... Apis mellifera L. with little brood in order to ... varroa, control, lemon juice...

[8] www.ncbi.nlm.nih.gov/pubmed/20069828

Removal of drone brood from Apis mellifera (Hymenoptera: Apidae) colonies to control Varroadestructor ... The parasitic mite Varroa destructor Anderson \& Trueman...

[9] www.beeculture.com/breeding-mite-biting-bees-to-control</... Breeding Mite-Biting Bees to Control Varroa. ... as a Varroa mite (Varroa destructor) control.... of honeybees Apis mellifera to the mite Varroa destructor over ... 